DOI 10.37882/2500-3682.2021.06.13

\title{
ВЗАИМОСВЯЗЬ ПОКАЗАТЕЛЕЙ ПСИХОЛОГИЧЕСКОГО БЛАГОПОЛУЧИЯ И ОБРАЗА ТЕЛА У ЖЕНЩИН ЗРЕЛОГО ВОЗРАСТА
}

\section{RELATIONSHIP RELATIONSHIP OF PSYCHOLOGICAL WELL-BEING AND BODY IMAGE IN MATURE WOMEN \\ S. Nikiforova}

Summary: The article presents the results of an empirical study of the relationship between indicators of psychological well-being and body image in women of mature age. Decrease in physical strength and attractiveness is one of the many problems that a person faces during the midlife crisis and beyond. For those who previously relied on their physical qualities and attractiveness, middle age can be a period of severe depression. On the basis of the revealed interconnection, it can be concluded that the phenomena studied by us are interdependent: the characteristics of the bodily image of the Self are interconnected with the indicators of the psychological well-being of the women under study. These data can be used as the basis for a program of psychological support for harmonizing the body image of women of mature age.

Keywords: women, mature age, psychological well-being, body image.

\section{Актуальность}

$\mathrm{O}$ дним из направлений развития гендерных исследований в психологии является «женская психология». «Женские исследования» (women studies) направлены на решение задачи выявления особенностей женского опыта и психологических проблем (Р. Хоф). Как отмечает И.С. Клецина, проблема половой дифференциации в рамках этого направления приобрела новый ракурс. В основном исследования «женской психики» ориентированы на психологическую практику, выполняются в контексте психологической помощи женщинам, пострадавшим в результате психического или физического насилия, и, чаще всего, не находят отражения в научных публикациях. Среди немногих авторов, касающихся проблем женской психологии, - Ю.Е. Алешина, С. Бем, Ш. Берн, И.С. Кон.

В рамках тендерной психологии близкими к теме нашего исследования являются работы, посвященные выявлению особенностей самооценок у мальчиков и девочек, юношей и девушек (Я.И. Михайловский, О.М. Мороз, Н.Н. Обозов, И.В. Тельнюк), анализу степени выраженности отдельных компонентов самоотношения у мужчин и женщин (Т.Н. Курбатова, Я.В. Куус), взаимосвязи образа

\author{
Никифорова Светлана Владимировна \\ Аспирант, ФГБОУ ВО «Красноярский государственный \\ медицинский университет им. В.Ф. Войно-Ясенецкого», \\ г. Красноярск \\ 583050@mail.ru
}

Аннотация: В статье представлены результаты эмпирического исследования взаимосвязи показателей психологического благополучия и образа тела у женщин зрелого возраста. Убывание физических сил и привлекательности - одна из многих проблем, с которыми сталкивается человек в годы кризиса среднего возраста и в последующем. Для тех, кто полагался ранее на свои физические качества и привлекательность, средний возраст может стать периодом тяжелой депрессии. На основании выявленной взамосвязи можно сделать заключение о том, что исследуемые нами феномены взаимообусловненны: характеристики телесного образа Я взаимосвязаны с показателями психологического благопочия исследуемых женщин. Эти данные возможно положить в основу программы психологического сопровождения гармонизации образа тела женщин зрелого возраста.

Ключевые слова: женщины, зрелый возраст, психологическое благополучие, образа тела.

тела и самоотношения у старшеклассников (Д.В. Желателев). Обзор литературы показал, что недостаточно изученным остается вопрос об особенностях психологического благополучия в соотношении с образом тела у женщин зрелого возраста.

Образ тела является одним из компонентов «Я-концепции» личности. Осознание и принятие своей телесности, адекватность восприятия своего тела и отношения к своей личности в целом, а также успешная социальная адаптация зависят от развития образа тела, его совершенствования и преодоления недостатков его формирования. По данным У. Джемса, в мире опубликовано более 2000 психологических исследований, посвящённых проблеме «Я», предметами которых становятся: структура и компоненты «Я»; психические процессы и операции, при помощи которых человек «осознаёт, оценивает, концептуализирует себя и своё поведение»; психологические функции самосознания: адекватность образа «Я», частных самооценок, их роль в саморегуляции поведения [1].

Исследователи выделяют различные «образы Я»: реальное, зеркальное, идеальное (В.В. Сизикова, В.В. Столин, Н. Толстых), «образ тела», «схема тела» (А.Н. Дороже- 
вец, В.Е. Каган, А.А. Налчаджян, Е.Т. Соколова), социальное «Я» (Ш. Самуэль), феноменальное, беспомощное, межперсональное, фальшивое «Я» (В.В. Столин), настоящее, динамическое, фактическое, вероятное, идеализированное «Я» (Розенберг), ретроспективное, проспективное «Я» (Н.И. Сарджавеладзе). Также в «Я-концепции» выделяется три компонента: «Я-реальное», «Я-идеальное» и «Я-зеркальное». Каждый из этих компонентов, в свою очередь, может включать в себя такие аспекты, как: физическое Я, социальное Я, умственное Я, эмоциональное Я. Поэтому «Я-концепция» может существовать на следующих уровнях: физическом Я-образе (схема тела), социальном (социальные идентичности: половая, возрастная, этническая, гражданская, социальноролевая), дифференцирующем образе Я (знания о себе в сравнении с другими людьми). Между «Я-образами» могут быть различные соотношения, например, «идеализированное Я» может включать характеристики «настоящего, идеального, будущего Я»; между «идеальным Я» и «представляемым Я» может быть конфликт. В.В. Сизикова изучала положительное влияние «Я-образов» друг на друга, в частности, мотивационное воздействие «идеального Я». На наш взгляд, достаточно структурированную информацию о подструктурах «Я-концепции» даёт А.А. Налчаджян. Одним из её важных компонентов он считает «образ тела» («телесное Я»): субъективное восприятие тела, в том числе внешности; идеальный образ тела (сравнение и идентификация своего тела с телами других и «идеала») [1].

Период зрелого возраста женщин характеризуются рядом морфологических и функциональных особенностей. Его условно делят на первый период (22-35 лет) и второй (36-55 лет) [5]. Зрелость - наиболее продолжительный период онтогенеза, характеризующийся тенденцией к достижению наивысшего развития духовных, интеллектуальных и физических способностей человека. Женщины зрелого возраста составляют основной контингент женщин, занятых в производственной сфере. На них возложена социальная функция материнства и воспитания детей. Зрелый возраст характеризуется периодом двигательного дефицита, в отличие от юношеского возраста, который признан периодом биологического оптимума.

В возрасте 25-30 лет, а иногда и ранее начинаются процессы инволюции двигательной функции, которые, как и процессы биологического развития, идут не параллельно, а гетерохронно. Наблюдается снижение функциональных возможностей, особенно дыхания и кровообращения.

В периоде второго зрелого возраста (36-55 лет) активизируются инволюционные процессы в организме, наступают выраженные возрастные изменения. Особенностями периода второго зрелого возраста являются: снижение объема потребления кислорода на 1 кг веса и теплопродукции на 1см поверхности тела; уменьшение гормональной функции; ухудшение эластичности тканей; атрофия мышц и снижение содержания в них энергетических веществ; ухудшение сократительной способности миокарда; замедление кровотока, уменьшение объема циркулирующей крови; изменение эластичности сосудов; снижение возбудимости дыхательного центра; нарушение жирового и углеводного обменов, затруднение образования белковых соединений. Для этого периода характерны изменения в опорно-двигательном аппарате, ограничение подвижности суставов и грудной клетки. Во втором зрелом возрасте наблюдаются изменения в деятельности нервной системы (снижение подвижности нервных процессов, затруднение образования новых рефлекторных связей, удлинение реакций, ухудшающих ориентировку, нарушение регуляции, изменения психики) [3].

Проблема позитивного психологического функционирования стала привлекать внимание исследователей, начиная с середины 20-го века, соотнося экзистенциальную и гуманистически ориентированную психологию с принципом целостности в подходе к пониманию личности, а также с интерпретацией личностного образа жизни - существование человека как уникального целого с уникальным жизненным опытом, внутренним миром, с уникальной реакцией на обстоятельства его жизни.

Такой подход требует введения концепции, которая характеризовала бы как степень позитивного функционирования личности, так и степень удовлетворенности человека собой и своей жизнью. Таким показателем может служить «психологическое благополучие» личности.

Современная отечественная психология не имеет общепризнанного понятия «психологическое благополучие личности». Несмотря на широкое использование этого термина в научной и научно-популярной литературе, единого определения не существует. Часто это означает ряд понятий, которые близки, но не идентичны по значению, таких как: «психическое здоровье», «нормальный», «нормальная и аномальная личность», «позитивный образ жизни», «эмоциональный комфорт», «качество жизни», «внутренняя картина здоровья, болезни», «зрелая личность», «самореализующаяся личность», «полноценнофункционирующая личность».

Теоретическую основу для понимания феномена психологического благополучия заложили исследования Н. Брэдберна. Он вводит понятие «психологическое благополучие» и отождествляет его с субъективным ощущением счастья и общего удовлетворения жизнью. Кроме того, сам автор ссылается на аристотелевское описание понятия «эвдемония» как отражающего сущность психологического благополучия. Н. Брэдберн отмечает, что он 
не подразумевает под понятием психологическое благополучие ряд других широко используемых понятий, таких как самоактуализация, самооценка, сила эго, автономия, но в то же время исследователь отмечает, что, возможно, эти понятия имеют области взаимного пересечения.

Важным вкладом в проблему понимания феномена психологического благополучия стала работа Э. Динера. Этот автор вводит понятие «субъективное благополучие». На самом деле, содержание этого термина очень близко к интерпретации психологического благополучия, которая была предложена в концепции Н. Брэдберна. Субъективное благополучие, по мнению исследователя, состоит из трех основных компонентов: удовлетворенности, приятных эмоций и неприятных эмоций, все эти три компонента вместе образуют единый показатель субъективного благополучия. Как отмечает сам автор, речь идет о когнитивной (интеллектуальная оценка удовлетворенности различными сферами своей жизни) и эмоциональной (наличие плохого или хорошего настроения) стороны самопринятия. Э. Динер считает, что большинство людей так или иначе оценивают происходящее с ними с точки зрения «хорошо - плохо», но такая интеллектуальная оценка всегда имеет соответственно окрашенную эмоцию [4].

Несмотря на схожие интерпретации структуры психологического благополучия Н. Брэдберном и Э. Динером, последний не считает их прямыми аналогами. Он считает, что субъективное благополучие является лишь компонентом психологического благополучия, и при этом он отмечает, что для описания последнего необходимо ввести дополнительные характеристики [2]. Другим автором, предложившим свою теорию психологического благополучия, была американская исследовательница, доктор психологии Кэрол Рифф. Во многих отношениях, продолжая традиции, заложенные Н. Брэдберном, она, тем не менее, критически пересматривает его взгляд на психологическое благополучие как на баланс между позитивным и негативным аффектами. Выдвигая тезис о том, что гедонистическое решение проблемы психологического благополучия страдает определенным ограничением, автор создает свою собственную теорию, которая основывалась на основных понятиях, которые так или иначе связаны с понятием психологического благополучия и относящиеся к проблеме позитивного психологического функционирования (теории А. Маслоу, Роджерса К., Аллпорта Г., Юнга К., Эриксона Е., Бюлера С., Ньюгартена Б., Яходы М., Биррена Д.). Подобный подход позволил ей обобщить и определить шесть основных компонентов психологического благополучия: самопринятие, позитивные отношения с окружающими, автономность, управление окружающей средой, жизненные цели, личностный рост.
В настоящее время, существует множество разрозненных и противоречивых фактов, различных методологических установок, отсутствует общепризнанная и устоявшаяся терминология, связанная с психологическим благополучием человека и образом тела. Отечественная психология располагает еще недостаточными теоретическими и практическими данными по этой проблеме. В настоящий момент, в социальной психологии существует лишь немногочисленное число работ, посвященных проблеме гендер - социальные атрибуты внешнего облика C. H. Яременко, D. Kyle. и др.; изучающие представления о способах оформления внешнего облика маскулинной, феминной личности А.А. Бодалев, В.А. Лабунская. Нет четко установленных закономерностей влияния самого содержания Образа Физического Я, сформированного в процессе социального взаимодействия, его составляющих, его формально-структурных характеристик, как на частные самооценки, так и глобальное отношение к себе.

Наше исследование было направлено на изучение взаимосвязи показателей психологического благополучия и образа тела у женщин зрелого возраста. База исследования Выборка исследования 40 женщин в возрасте от 36 до 45 лет.

Методы исследования. Методика определения телесного образа Я разработана и опубликована в 1949 году основателем одной из школ по телесно-ориентированной психотерапии - М. Фельденкрайзом. Автор подчеркивает, что телесный образ Я, или бессознательный образ тела - одна из глубинных и базовых структур личности, влияющая на всю личность в целом и на её движение по жизненному пути. С него можно считывать информацию об особенностях структуры характера, актуальной проблематике, мышечном панцире и травмах развития [5].

Опросник «Шкалы психологического благополучия» Кэрол Рифф. Методика представляет собой адаптированный на русском языке вариант англоязычной методики The scales of psychological well-being, разработанный К. Рифф. Методика была несколько раз валидизирована в различных варинтах. Наиболее распространённым является вариант из 84 пунктов, послуживший основой для двух русскоязычных версий: в 2005 году опросник был адаптирован и валидизирован Т.Д. Шевеленковой и Т.П. Фесенко, в 2007 году - Н.Н. Лепешинским[7].

Анализ данных по методике определения телесного образа Я показал, что большинство (50\%) женщин имеют бесполый тип телесного образа Я. Наличие этого типа свидетельствует о психологической травме на шизоидной или оральной стадиях развития, возможном нарушении половой идентичности и глобальном страхе перед миром. Психотерапевтическая помощь таким клиентам должна вестись в русле работы со страхом, 
формировать психологическую устойчивость. У 25\% исследуемых зафиксирован мускулинный тип образа тела, что указывает на гипертрофированную мужественность, задавленную женственность, проявления настойчивости, упорства и ригидной жизненной позиции. В психологической работе следует сделать акцент на повышение пластичности, адаптивности. У одной женщины (5\%) зафиксирован феминный тип образа тела, что характеризуется большим количеством страхов в контакте с окружающим социумом, так и с миром вообще. Говоря о дальнейшей психологической работе, следует выделить следующие линии: работа со страхами, адаптация в социуме. У 15\% исследуемых выявлен андрогинный тип телесного образа Я. Поведение таких индивидов достаточно дихотомично, свойства - амбивалентны. Психологическая помощь должна быть направлена на интеграцию личности, различных её сторон в единое целое.

Анализируя результаты исследования по методике «Шкалы психологического благополучия» Кэрол Рифф можно отметить следующее:

По данным шкалы «Позитивные отношения с окружающими», высокие (20\%) и средние показатели (80\%) свидетельствуют о наличии у испытуемых близких, приятных, доверительных отношений с окружающими; желания проявлять заботу о других людях; способности к эмпатии; наличии навыков, помогающих устанавливать и поддерживать контакты с другими людьми. Кроме этого, данная характеристика включает в себя желание быть гибким во взаимодействии с окружающими, умение прийти к компромиссу. Низких показателей по этой шкале не наблюдалось, которые свидетельствовали бы об одиночестве, неспособности устанавливать и поддерживать доверительные отношения, не желании искать компромиссы, замкнутости.

Из результатов, полученных по шкале «Автономия» можно сказать, что 20\% испытуемых имеют высокие показатели, а 65\% - средние. Исходя из этого, можно говорить о том, что испытуемые имеют такие качества, как независимость, способность противостоять социальному давлению в своих мыслях и поступках, а также способны регулировать собственное поведение и оценивать себя исходя из собственных стандартов. Озабоченность ожиданиями и оценками других, ориентация на мнение других людей при принятии важных решений и неспособность противостоять социальному давлению в мыслях и поступках характерны для людей с низкими показателями по данной шкале - 15\% испытуемых.

Анализируя полученные результаты по шкале «Управление средой», можно сделать следующие выводы: у испытуемых имеется чувство уверенности и компетентности в управлении повседневными делами, способность эффективно использовать различные жизненные обсто- ятельства, умение самому выбирать и создавать подходящий контекст для реализации личных потребностей и ценностей, а также умение осуществлять разнообразные виды деятельности. Данные качества присущи 75\% респондентам, причем у $20 \%$ испытуемых эти качества находятся на более высоком уровне. Низкие показатели (5\%): трудности в управлении повседневными делами, чувство неспособности улучшить или изменить окружающие обстоятельства, отсутствие чувства контроля над внешним миром.

По шкале «Личностный рост» у $35 \%$ респондентов высокие и у $60 \%$ средние значения. Из этого следует, что испытуемые обладают чувством продолжающегося развития и реализации своего потенциала, видят свой рост и экспансию, открыты новому опыту, наблюдают все большее совершенствование себя и своего поведения с течением времени. У 5\% исследуемых этот компонент психологического благополучия находится на низком уровне, который говорил бы о переживании личностной стагнации. Отсутствует ощущение личностного прогресса с течением времени. Ощущается скука и незаинтересованность жизнью. Ощущение неспособности усваивать новые навыки.

Результаты, полученные по шкале «Цели в жизни», свидетельствуют о высоком уровне психологического благополучия у $35 \%$ респондентов и в среднем у $60 \%$. Отсюда следует, что им присущи наличие жизненных целей и чувство осмысленности их прошлого и настоящего. Они сформировали убеждения, которые дают цель жизни, а также имеют основания и причины для жизни. Часть испытуемых (5\%) характеризуются низкими баллами по этой шкале, что означает, что им не свойственно: чувство значимости жизни и чувство направленности. Нет недостатка в целях, нет взглядов и убеждений, которые придают смысл жизни. Они не видят цели и в своем прошлом.

Результаты по шкале «Самопринятие». Высокие 40\% и средние $40 \%$ значения. Это означает, что они обладают позитивным отношением к себе и своему прошлому, осознают и принимают разные стороны своего «Я», включая как положительные, так и отрицательные качества. Для 20\% исследуемых нами людей данной выборки характерны низкие баллы по данной шкале, а значит им не свойственно: недовольство самим собой, они разочарованы в собственном прошлом, обеспокоены некоторыми чертами собственной личности, не принимают себя. Для них характерно желание быть другими.

Таким образом, на основании полученных данных в процессе исследования, можно говорить о том, что только высокие и средние показатели наблюдались в шкале «позитивные отношения». В шкалах «автономия» и «самопринятие» были смешанные показатели. Что касаемо 
низких показателей (5\%) они выявились в шкалах «личностный рост», «управление средой» и «цели в жизни». Максимальный процент низких показателей наблюдался в шкале «самопринятие» (20\%).

С целью выявления взаимосвязей между изучаемыми характеристиками мотивационно-ценностных предпочтений курсантов военного института данные иследования были обработаны нами с помощью программы «STATISTICA - 16.0». Для выявления взаимосвязей между изучаемыми характеристиками мы использовали коэффициент ранговой корреляции Спирмена. Шкала «телесного образа Я» положительно коррелирует со всеми шкалами методики «Шкалы психологического благополучия» Кэрол Рифф: . «Позитивные отношения с окружающими» $\left(0,71\right.$ при $\left.r^{*} \geq 0,5\right)$; «Цели в жизни» $(0,68$ при $\left.r^{*} \geq 0,5\right)$; «Личностный рост» $\left(0,66\right.$ при $\left.r^{*} \geq 0,5\right)$; «Автономия» $\left(0,68\right.$ при $\left.r^{*} \geq 0,5\right)$; «Самопринятие» $\left(0,81\right.$ при $\left.r^{*} \geq 0,5\right)$. На основании выявленной взамосвязи можно сделать заключение о том, что исследуемые нами феномены взаимообусловненны: характеристики телесного образа Я взаимосвязаны с показателями психологического благопочия. Эти данные возможно положить в основу программы психологического сопровождения «Возможности гармонизации образа тела женщин зрелого возраста» разрабатываемую нами в рамках диссертационного исследования.

Таким образом, телесный образ Я, или образ тела - одна из глубинных и базовых структур личности, влияющая на всю личность в целом и на ее движение по жизненному пути, с него можно считать информацию об особенностях структуры характера, актуальной проблематике, травмах развития. Образ тела - это отражение своего тела в сознании личности, вся совокупность знаний и телесного опыта личности, как осознаваемой части, так и неосознаваемой. Внутренняя картина собственного тела, особенность индивидуального самовосприятия своего тела, внутренний образ тела может отличаться от реального телесного состояния. Образ тела формируется у человека на протяжении всей жизни под влиянием различных факторов, как внешних, так и внутренних. Таким образом, образ тела является важной составной частью знаний о себе и самовосприятия и оказывает значительное влияние на чувства, мысли и поведение человека в течение всей жизни.

\section{ЛИТЕРАТУРА}

1. Баранская, Л.Т. Образ тела как предиктор нарушения адаптации молодежи в социальной среде // Молодое поколение XXI века: Актуальные проблемы социально-психологического здоровья /Л.Т. Баранская, С.С. Татауров. М.: «ИГРА». 2019. - С. 331-335.

2. Брэдберн, Н. Структура психологического благополучия / Н. Брэдберн // - Ярославль.: Инфра., 2015. - 13 с.

3. Николаева, В.В. Психология телесности: методологические принципы и этапы клинико-психологического анализа. // Арина Г.А., Николаева В.В. Междисциплинарные проблемы психологии телесности., М., Изд. Московского Гуманитарного Университета, 2017.- 230с.

4. Стрелков, И.А. О проблеме психологического благополучия / неблагополучия в современной психологии / И.А. Стрелков. - М., 2019. - 67 с.

5. Тхостов, А.Ш. Психология телесности / А.Ш. Тхостов. М.: Смысл, 2012. - 252 с.

6. Фесенко, П.П. Что такое психологическое благополучие? Краткий обзор основных концепций / П.П. Фесенко // Научные труды аспирантов и докторантов. - М.: Издательство Московского гуманитарного университета, 2015. - Выпуск 46. - С. 35-48.

7. Шевеленкова, Т.Д., Фесенко, П.П. Психологическое благополучие личности (обзор основных концепций) / Т.Д. Шевеленкова, П.П. Фесенко // Психологическая диагностика, 2015. - №3. - С. 95-129.

8. Cash, T.F. The development and validation of the Body-Image Ideals Questionnaire // Journal of Personal Assessment. 1995. Vol. 64. P. 466-477.

9. Cash, T.F. Looks Aren't Everything (To Everybody) // Journal of Social Behavior and Personality. 1992. Vol. 7. Iss. 4. P. $621-630$. 